\title{
AMP-activated protein kinase and its regulation by adiponectin and interleukin-6
}

\author{
Meghan Kelly, Neil B. Ruderman and Eva Tomas \\ Diabetes Unit, Section of Endocrinology, Boston University School of Medicine, Boston, Massachusetts, USA
}

\begin{abstract}
AMP-activated protein kinase (AMPK) is a fuel-sensing enzyme that responds to decreases in cellular energy state by activating processes that generate adenosine triphosphate (ATP) (e.g. fatty acid oxidation), and inhibiting others that consume ATP but are not acutely necessary for survival (e.g. fatty acid, triglyceride and protein synthesis). In contrast, sustained decreases in AMPK or a failure to activate it appropriately have been implicated in the pathogenesis of the metabolic syndrome. Recent studies suggest that various hormones can activate or inhibit AMPK. One of these hormones, adiponectin (Adn), an adipokine released by the fat cell, activates AMPK in liver, muscle, primary rat adipocytes, cultured endothelium and almost certainly other cells. Low plasma levels of Adn are associated with the metabolic syndrome; thus, in both humans and experimental animals, they are often accompanied by obesity, insulin resistance, ectopic lipid deposition, and a predisposition to both type 2 diabetes and atherosclerotic heart disease. Recent studies suggest that thiazoledinediones (TZDs), agents used to treat diabetes because they diminish insulin resistance, exert this effect in great measure by increasing the synthesis and release of adiponectin by the adipocyte and secondarily increasing AMPK activity in the liver and other tissues. Another cytokine that has been shown to activate AMPK is interleukin-6 (IL-6). Studies in IL-6 knockout (KO) mice have revealed that AMPK activity is diminished in their muscle and adipose tissue at 3 months of age and that, like the adiponectin KO mice, they are predisposed to obesity, glucose intolerance and hypertriglyceridemia. Likewise, when bred on an Apo $\mathrm{E}^{-1-}$ they develop more severe atherosclerosis than control mice. Whether AMPK activation by other means prevents the development of the metabolic syndrome in the IL-6 or adiponectin KO mice remains to be determined.
\end{abstract}

Keywords: AMPK, adiponectin, Interleukin-6, metabolic syndrome, T2DS

Abbreviations: ACC: acetyl coenzyme A carboxylase; Adn: adiponectin; AICAR: 5-aminoimidazole-4carboximide 1- $\beta$-D-ribofuranoside; AMP: adenosine monophosphate; AMPK: AMP-activated protein kinase; Apo: apolipoprotein; ATP: adenosine triphosphate; $C A M K K-\beta$ : calmodulin-dependent protein kinase kinase- $\beta$; CoA: coenzyme A; DOG: deoxyglucose; EDL: extensor digitorum longus; HMW: high molecular weight species; ICAM: intercellular adhesion molecule; IL-6: interleukin-6; KO: knockout; NF- $\kappa B$ : nuclear factor- $\kappa B$; PPAR: peroxisome proliferator activated receptor; TZD: thiazoledinedione; UCP: uncoupling protein; VCAM: vascular cell adhesion molecule.

\section{Introduction}

A denosine monophosphate-activated protein kinase (AMPK) is a fuel-sensing enzyme that responds to decreases in cellular energy state. During such states as glucose deprivation and exercise, AMPK activation restores adenosine triphosphate (ATP) levels by activating processes that generate ATP (e.g. fatty acid oxidation), and inhibiting others that consume ATP but are not acutely necessary for survival (e.g. fatty acid, triglyceride and protein synthesis). In contrast, sustained decreases in AMPK or a failure to activate it appropriately have been implicated in the pathogenesis of the metabolic syndrome. Recent studies suggest that various hormones can activate or inhibit AMPK; however, the mechanism by which they do so and in some instances the physiological relevance of their effects is incompletely understood. This review covers the relationship between AMPK and two of these hormones, adiponectin (Adn) and interleukin 6 (IL-6). Adn, an adipokine released by the fat cell, activates 
Kelly $M$ et al.

AMPK in liver, muscle, primary rat adipocytes, cultured endothelium and almost certainly other cells. Low plasma levels of Adn in both humans and experimental animals are associated with obesity, insulin resistance, ectopic lipid deposition (i.e. characteristics of the metabolic syndrome) in multiple tissues, and a predisposition to both type 2 diabetes and atherosclerotic heart disease. The extent to which these effects of Adn lack are due to decreased AMPK activity remains to be determined. In support of such a possibility, treatment with thiazolidinediones (TZDs), agents used to treat diabetes because they diminish insulin resistance, have been shown to increase both plasma Adn and tissue AMPK activity. In addition, it has been shown that the effects of TZDs on insulin sensitivity and AMPK are diminished or lost in Adn knockout (KO) mice (1).

Whereas the adipocyte releases upward of 20 hormones, to date the only hormone known to originate in muscle is IL-6. IL-6 is synthesized and released by muscle in large amounts during sustained exercise, during which its concentration in plasma may increase 50-100-fold (2). It has been suggested that it acts on the fat cell to increase lipolysis when the exercising muscle needs additional fatty acids as a fuel. IL-6 activates AMPK in both adipose tissue and muscle, and in an IL-6 knockout mouse, the activity of AMPK in these tissues is diminished even at rest (3). Previous studies $(4,5)$ had shown that these mice appear normal at 3 months of age, but at the age of 9 months they are obese, dyslipidemic and glucose intolerant. Likewise, when bred on an apolipoprotein (Apo) $\mathrm{E}^{-/-}$background they have been shown to develop more severe atherosclerosis than control mice $(6,7)$. Whether the decrease in AMPK activity at 3 months of age contributes to the later development of the metabolic syndrome phenotype in these mice is currently under investigation.

\section{The metabolic syndrome}

The metabolic syndrome can be defined as "a state of metabolic dysregulation characterized by insulin resistance, hyperinsulinemia and a predisposition to type 2 diabetes, dyslipidemia, atherosclerotic vascular disease, hypertension and other disorders". Affected individuals are typically obese or overweight, or show more subtle manifestations of increased adiposity such as an increase in abdominal fat or fat cell size. In addition, they may have a decreased capacity for exercise and often show evidence of low grade inflammation, a procoagulant state and mitochondrial dysfunction (8).

The metabolic syndrome is important for two reasons: first, it is a target for the prevention and therapy of the multiple disorders with which it is associated; and secondly, it is extremely common. According to the widely accepted guidelines of the Adult Treatment Panel, upwards of 50 million people in the USA over 20 years of age have the metabolic syndrome, and this number is likely to increase further as obesity and overweight continue to become more prevalent (8). This group has recently proposed that the metabolic dysregulation that underlies the metabolic syndrome involves the fuel-sensing enzyme AMPK (9).

\section{AMP-activated protein kinase structure and function}

AMPK is a heterotrimer consisting of a catalytic $\alpha$-subunit and regulatory $\beta$ - and $\gamma$-subunits. Hardie and Carling (10) first noted the dependence of AMPK on cellular energy state, and more specifically the AMP:ATP ratio. They proposed that a cascade of events initiated by AMPK is part of a cell's response to stresses that deplete ATP and threaten its viability. More specifically, they proposed that AMPK acts a "fuel gauge" that when activated stimulates processes that generate ATP and inhibits others that consume ATP, but are not acutely necessary for survival (Fig. 1). Early studies revealed that such activation of AMPK occurs in response to a wide variety of factors that deplete cellular energy stores, including glucose deprivation, hypoxia, ischemia and muscle exercise. Among the events simulated by AMPK activation (Fig. 1) are fatty acid oxidation, glucose transport (in skeletal muscle and the heart) and glycolysis (heart). Among the processes inhibited at least for finite periods are the synthesis of triglycerides and proteins. As shown in Fig. 2, rising intracellular AMP displaces ATP bound to the $\gamma$-subunit of AMPK, altering its structure. It is thought that this structural change may make AMPK less susceptible to dephosphorylation and inactivation by protein phosphatases and more susceptible to activation and phosphorylation on Thr172 in its $\alpha$-subunit (10). To date, two such AMPK kinases have been identified. One of them is LKB1, a tumor suppressor that appears to mediate AMPK activation in response to changes in energy state $(11,12)$, and the other calmodulin-dependent 


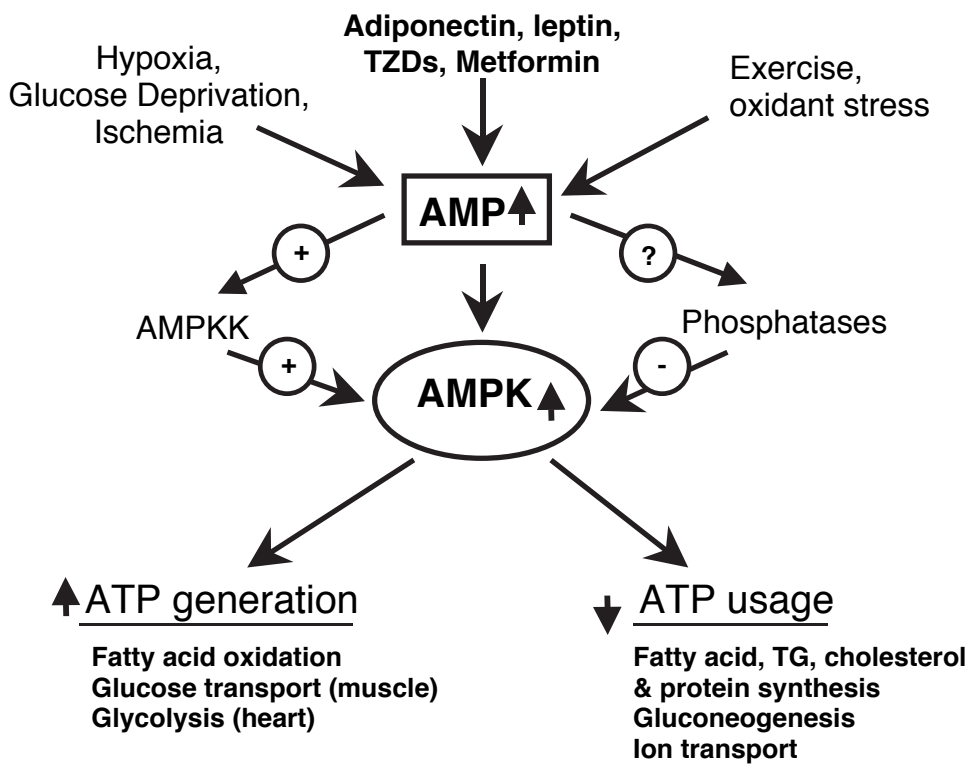

Fig. 1. AMP-activated protein kinase (AMPK) activation and its effect on cellular energy state. AMPK activation concurrently leads to an increase in cellular processes that generate adenosine triphosphate (ATP) and a decrease in those processes that use ATP, but are not immediately needed for cell survival. AMPK activation has been attributed to ATP depletion, which leads to changes in the adenosine monophosphate (AMP): ATP ratio. It is currently suspected, although not definitively proven, that metformin, adiponectin and leptin activate AMPK by altering the energy state of a cell. [Modified from Ruderman and Prentki (9).] TG: triglyceride; TZD: thiazoledinedione.

protein kinase kinase- $\beta$ (CAMKK- $\beta)$, an enzyme that is activated by $\mathrm{Ca}^{2+}(13,14)$. In contrast to LKB1, CAMMK- $\beta$ does not appear to require a change in energy state to activate AMPK.

Recently it has been demonstrated that AMPK can also be activated by leptin and a number of other hormones (15). Furthermore, it has been shown that a lack of these hormones or in some instances their receptors predisposes to obesity, insulin resistance, inflammation and, in genetically predisposed animals and humans, to diabetes and other disorders associated with the metabolic syndrome (9).

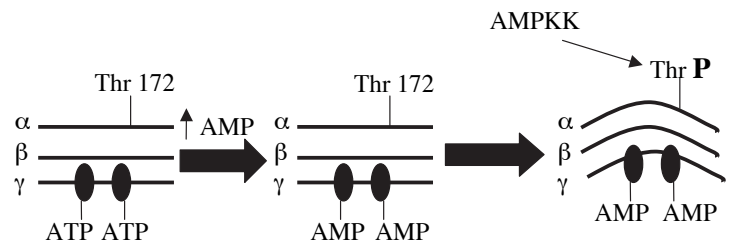

Fig. 2. Activation of AMP-activated protein kinase (AMPK). Adenosine triphosphate (ATP) binds to specific domains on the $\gamma$ subunit of AMPK; however, when intracellular adenosine monophosphate (AMP) increases (due to glucose deprivation, hypoxia, etc.) ATP is displaced by AMP owing to its higher binding affinity. The binding of AMP alters the structure of AMPK, thus making it a better substrate for at least one upstream kinase (labeled AMPKK), the tumor suppressor LKB1.

\section{Adiponectin}

Adn is secreted from differentiated adipocytes and circulates in plasma as three different forms: trimer, hexamer and high molecular weight (HMW) species (16). Its levels in plasma, and in particular that of the HMW form are decreased in obesity, type 2 diabetes, various insulin-resistant states and coronary artery disease (17). Despite this, the identity of the biologically active form(s) of Adn remains unclear. Fruebis et al. showed that the globular subunit of Adn (g-Adn), which is not found in the circulation, increases fatty acid oxidation in incubated mouse skeletal muscle and cultured muscle cells (18). They also found that its administration in vivo prevents obesity and increases insulin sensitivity in fat-fed rats. Because these effects are similar to those observed when AMPK is activated by muscle contraction or treatment with the AMPK activator 5 -aminoimidazonle-4-carboximide 1- $\beta$-D-ribofuransoside (AICAR), the present group assessed whether g-Adn activates AMPK.

As shown in Fig. 3, g-Adn increases AMPK activity and phosphorylation in incubated rat extensor digitorum longus (EDL) skeletal muscle. Similar findings were observed in muscle of C57BL/ $6 \mathrm{~J}$ mice following its intraperitoneal injection (19). In keeping with this, g-adiponectin also produced 
A

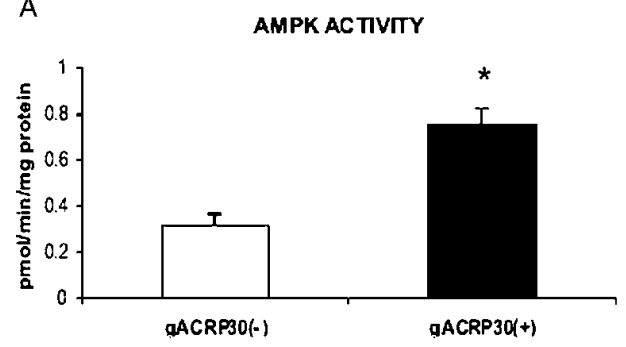

C

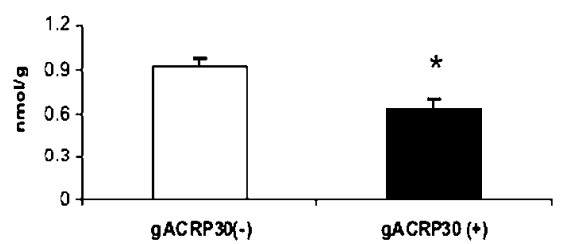

$B$

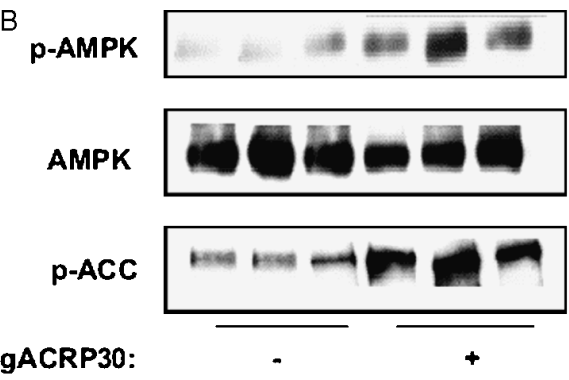

GLUCOSE UPTAKE

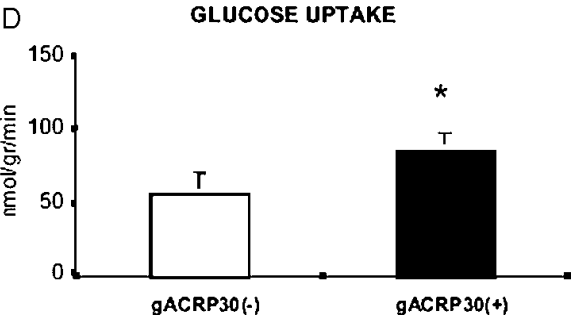

Fig. 3. Effects of incubation with gACRP30 on AMP-activated protein kinase (AMPK) signaling and related parameters in rat extensor digitorum longus (EDL). EDL muscles from $60 \mathrm{~g}$ rats were incubated for $30 \mathrm{~min}$ in the presence $(+)$ or absence $(-)$ of $\mathrm{gACRP} 30\left(2.5 \mu \mathrm{g} \mathrm{ml}{ }^{-1}\right)$ and analyzed for (A) $\alpha_{2}$-AMPK activity, (B) phosphorylated AMPK (P-AMPK) (Thr 172), total AMPK and phosphorylated acetyl coenzyme A carboxylase (P-ACC) (Ser 79), and (C) malonyl coenzyme A (CoA) concentration. Blots are representative of muscles of three to five animals. Measurements of AMPK activity and malonyl CoA concentration are means \pm SE $(n=5)$. (D) Effect of gACRP30 on glucose transport in rat EDL. [Taken from Wu et al. (20); used with permission.]

several well-known effects of AMPK activation in muscle, including a decrease in the concentration of malonyl-conenzyme A ( $\mathrm{CoA})$ and increases in the phosphorylation of acetyl-coenzyme A carboxylase (ACC) and the uptake of 2-deoxyglucose (2-DOG) (Fig. 3) Similar changes in AMPK and ACC have been described in primary rat adipocytes exposed to g-Adn (20) and in rodent liver following the administration of HMW Adn (21). In liver, HMW Adn has also been shown to diminish glucose production and the expression of gluconeogenic enzymes (22), and in obese rodents, it diminishes hepatic lipid accumulation (23). Collectively, these findings suggest that Adn may improve insulin sensitivity by a mechanism that involves AMPK.

In addition to these effects, Adn has been reported to diminish atherosclerosis in Apo E KO mice (24), and to inhibit tumor necrosis factor$\alpha$-induced increases in the expression of adhesion molecules such as vascular cell adhesion molecule-1 (VCAM-1) and intercellular cell adhesion molecule-

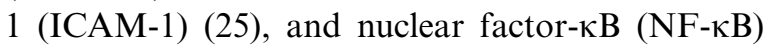
activation in cultured endothelium (26). The effects in cultured endothelium are similar to those reported for the AMPK activator AICAR (27).

In both humans and experimental animals, Adn expression in adipocytes and its level in plasma are increased by treatment with peroxisome proliferator activated receptor- $\gamma$ (PPAR- $\gamma$ ) agonists such as the TZDs (22). Earlier studies established that TZDs in vivo increase AMPK activity in rat liver and adipose tissue (28). To determine whether Adn plays a pivotal role in mediating this effect, the TZD rosiglitazone was administered by gavage for 2 weeks to control and Adn KO mice. As shown in Fig. 4, rosiglitazone failed to activate AMPK and decrease the concentration of malonyl-CoA in liver of the Adn KO mice (1). Similar results were found in skeletal muscle (data not shown). In keeping with these findings, glucose tolerance was less improved after rosiglitazone treatment in ob/ob mice lacking Adn than in ob/ob control mice.

\section{Interleukin-6}

IL-6 has long been recognized for its effects on the immune system, although it has other actions (29). In humans sustained, but modest, increases in its plasma concentration have been found in proinflammatory, insulin-resistant states, especially in the presence of obesity (30). Interest in the relationship between IL-6 and AMPK stemmed from observations made during exercise. Thus, the activity of AMPK increased in liver and adipose tissue, as well as muscle, in rats studied after a treadmill run, raising the possibility of its regulation by a systemic hormonal factor (31). That one such factor might 


\section{Liver}

A

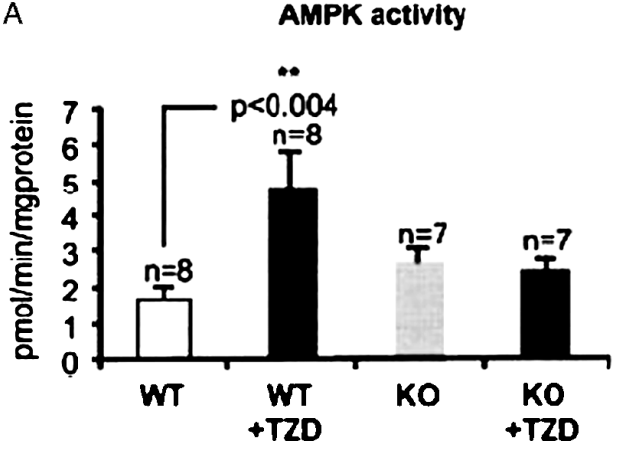

B

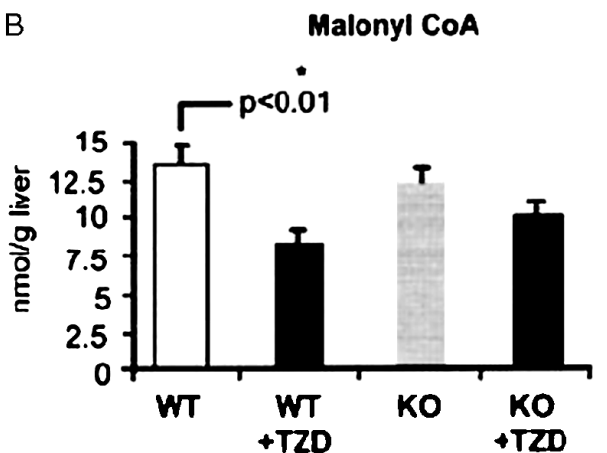

Fig. 4. Effect of the treatment with rosiglitazone on (A) AMP-activated protein kinase (AMPK) activity and (B) malonyl coenzyme A (CoA) concentration in vivo in wild-type (WT) and adiponectin knockout $(\mathrm{KO})$ mice. Mice were treated with $10 \mathrm{mg}^{\mathrm{kg}} \mathrm{body}^{-1}$ weight per day of rosiglitazone $[+$ thiazoledinedione $(\mathrm{TZD})]$ or vehicle by oral gavage. Results are means $\pm \mathrm{SE}(n=10) .{ }^{*} p<0.05$. [Modified from Nawrocki et al. (1); used with permission.]

be IL-6 was first suggested by the finding of Pederson and co-workers (32) that IL-6 is synthesized and released into the circulation by skeletal muscle during exercise in both humans and mice. They found that IL- 6 release was more or less proportional to the duration and intensity of the exercise (33), and that in humans it could lead to a 50-100-fold increase in plasma levels of IL-6 compared with baseline values (in contrast, only a two- to three-fold increase in plasma IL-6 occurs in obese insulin-resistant individuals; reviewed in ref. 30). Pedersen and co-workers also found that an

A Muscle in vitro

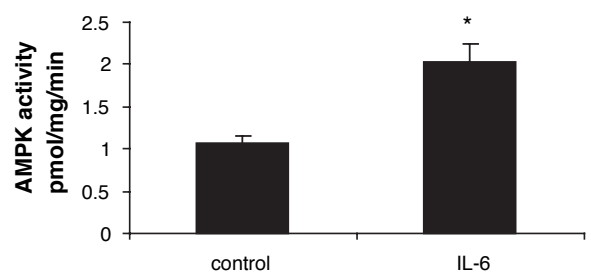

C Muscle in vivo

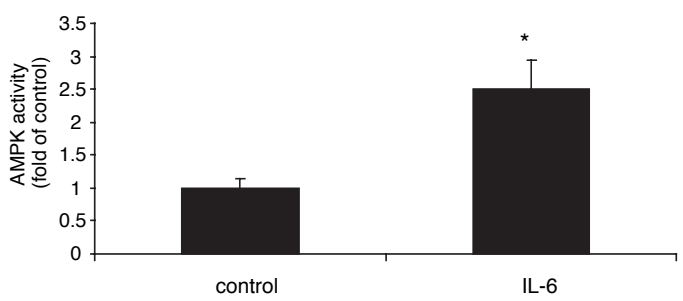

infusion of IL-6 into humans increases adipose tissue lipolysis and hepatic glucose production during exercise (34). Based on these findings they proposed that IL-6 released into the circulation during exercise is a signal to other tissues to provide for the energy needs of muscle as its endogenous fuel stores (e.g. glycogen) are depleted $(2,35)$.

The studies by Park in the present authors' unit and those of the Pedersen group $(2,33,36)$ led to a joint effort of the two laboratories to assess whether IL-6 activates AMPK. As shown in Fig. 5, it was found that IL-6 rapidly activates AMPK in both

\section{B Adipose in vitro}

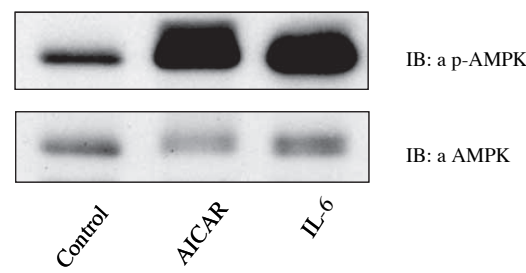

D Adipose in vivo

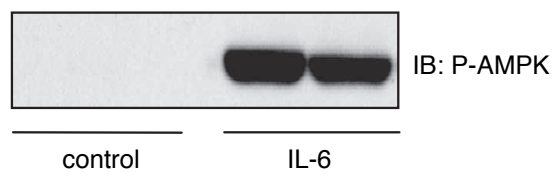

Fig. 5. AMP-activated protein kinase (AMPK) activation by interleukin-6 (IL-6) in (A) incubated rat extensor digitorum longus muscle; (B) cultured F442A adipocytes; and in vivo in (C) rat mixed gastrocnemius muscle, and (D) epididymal adipose tissue $1 \mathrm{~h}$ after an intraperitoneal injection of IL-6 $(2.5 \mu \mathrm{g})$. Results are means $\pm \operatorname{SEM}(\mathrm{A}, \mathrm{C})$ of four measurements. ${ }^{*} p<0.05$. Blots in (B) and (D) are representative of three studies. [Taken from Ruderman et al. (30); used with permission.] 
Kelly $M$ et al.

intact EDL muscle and F442a adipocytes (3). Likewise, an intraperitoneal injection of IL-6 (25 $\mathrm{ng} \mathrm{g}^{-1}$ rat weight) increased AMPK activity in both skeletal muscle and adipose tissue within $1 \mathrm{~h}$. The mechanism by which IL-6 activates AMPK has not been conclusively determined; however, preliminary data suggest that IL-6 induces alterations in the AMP:ATP ratio that correlate temporally with changes in AMPK activity (M Kelly, unpublished observations).

The physiological relevance of the interrelationship between IL-6 and AMPK was evaluated in the IL-6 KO mouse (5). These mice develop obesity, hypertriglyceridemia and glucose intolerance by 9 months of age. At 3 months of age they appear normal; however, AMPK activity in skeletal muscle and adipose tissue at rest was diminished by $75 \%$ and $50 \%$, respectively, and the absolute increases in plasma AMPK were markedly less than in littermate control mice, although they were not completely prevented (3). Preliminary data suggest that cardiolipin, a lipid that reflects mitochondrial electron transport capability, is diminished in white muscle of these mice, as is the expression of a mitochondrial uncoupling protein (UCP3) that is thought to protect against oxidative stress (30). In keeping with these findings, Faldt et al. (4) observed that preobese IL-6 KO mice (aged 3 months) have reduced exercise endurance and an elevated respiratory exchange ratio $(0.83 \pm 0.03$ vs $0.77 \pm 0.02)$, indicating a decreased rate of fatty acid oxidation. Both of these observations could be explained by their reduced AMPK activity (37). Further studies are needed to evaluate the role of IL-6 deficiency in the pathogenesis of the obesity, glucose intolerance and hypertriglyceridemia that develops later in these mice, as well as the increased severity of atherosclerosis that has been observed when they are cross-bred with $\mathrm{ApoE}^{-1-}$ mice (7). Also requiring study is why both a lack of IL-6 and a chronic, but low-grade, increase in its plasma concentration are associated with the metabolic syndrome.

\section{Acknowledgements}

The research described in this manuscript was supported by USPHS grants DK19514, DK07201 and P01-HL 068758, a research grant from the Juvenile Diabetes Research Founda- tion and a mentor-based fellowship from the American Diabetes Association.

\section{References}

1. Nawrocki AR, Rajala MW, Tomas E, Pajvani UB, Saha AK, Trumbauer ME, et al. Mice lacking adiponectin show decreased hepatic insulin sensitivity and reduced responsiveness to peroxisome proliferator-activated receptor gamma agonists. J Biol Chem 2006; 281: $2654-$ 60 .

2. Febbraio MA, Pedersen BK. Muscle-derived interleukin-6: mechanisms for activation and possible biological roles. FASEB J 2002; 16: 1335-47.

3. Kelly M, Keller C, Avilucea PR, Keller P, Luo Z, Xiang $\mathrm{X}$, et al. AMPK activity is diminished in tissues of IL-6 knockout mice: the effect of exercise. Biochem Biophys Res Commun 2004; 320: 449-54.

4. Faldt J, Wernstedt I, Fitzgerald SM, Wallenius K, Bergstrom G, Jansson JO. Reduced exercise endurance in interleukin-6-deficient mice. Endocrinology 2004; 145: 2680-6.

5. Wallenius V, Wallenius $\mathrm{K}$, Ahren B, Rudling $\mathrm{M}$, Carlsten H, Dickson SL, et al. Interleukin-6-deficient mice develop mature-onset obesity. Nat Med 2002; 8: 75-9.

6. Elhage R, Clamens S, Besnard S, Mallat Z, Tedgui A, Arnal $\mathrm{J}$, et al. Involvement of interleukin- 6 in atherosclerosis but not in the prevention of fatty streak formation by $17 \beta$-estradiol in apolipoprotein E-deficient mice. Atherosclerosis 2001; 156: 315-20.

7. Schieffer B, Selle T, Hilfiker A, Hilfiker-Kleiner D, Grote K, Tietge UJ, et al. Impact of interleukin-6 on plaque development and morphology in experimental atherosclerosis. Circulation 2004; 110: 3493-500.

8. Ruderman NB, Shulman G. The metabolic syndrome. In: Jameson JL, ed. Endocrinology. 5th edn. Philadelphia, PA: Elsevier; 2006. pp. 1149-116.

9. Ruderman N, Prentki M. AMP kinase and malonylCoA: targets for therapy of the metabolic syndrome. Nat Rev Drug Discov 2004; 3: 340-51.

10. Carling D. The AMP-activated protein kinase cascade a unifying system for energy control. Trends Biochem Sci 2004; 29: 18-24.

11. Hawley SA, Boudeau J, Reid JL, Mustard KJ, Udd L, Makela TP, et al. Complexes between the LKB1 tumor suppressor, STRAD $\alpha / \beta$ and MO25 $\alpha / \beta$ are upstream kinases in the AMP-activated protein kinase cascade. $\mathbf{J}$ Biol 2003; 2: 28.

12. Woods A, Johnstone SR, Dickerson K, Leiper FC, Fryer LG, Neumann D, et al. LKB1 is the upstream kinase in the AMP-activated protein kinase cascade. Curr Biol 2003; 13: 2004-8.

13. Woods A, Dickerson K, Heath R, Hong SP, Momcilovic $\mathrm{M}$, Johnstone SR, et al. $\mathrm{Ca}^{2+} /$ calmodulin-dependent protein kinase kinase-beta acts upstream of AMPactivated protein kinase in mammalian cells. Cell Metab 2005; 2: 21-33. 
14. Hawley SA, Pan DA, Mustard KJ, Ross L, Bain J, Edelman AM, et al. Calmodulin-dependent protein kinase kinase-beta is an alternative upstream kinase for AMP-activated protein kinase. Cell Metab 2005; 2: 9-19.

15. Kahn BB, Alquier T, Carling D, Hardie DG. AMPactivated protein kinase: ancient energy gauge provides clues to modern understanding of metabolism. Cell Metab 2005; 1: 15-25.

16. Tsao TS, Tomas E, Murrey HE, Hug C, Lee DH, Ruderman NB, et al. Role of disulfide bonds in Acrp30/ adiponectin structure and signaling specificity. Different oligomers activate different signal transduction pathways. J Biol Chem 2003; 278: 50810-7.

17. Kadowaki T, Yamauchi T. Adiponectin and adiponectin receptors. Endocr Rev 2005; 26: 439-51.

18. Fruebis J, Tsao TS, Javorschi S, Ebbets-Reed D, Erickson MR, Yen FT, et al. Proteolytic cleavage product of $30-\mathrm{kDa}$ adipocyte complement-related protein increases fatty acid oxidation in muscle and causes weight loss in mice. Proc Natl Acad Sci USA 2001; 98: 2005-10.

19. Tomas E, Tsao TS, Saha AK, Murrey HE, Zhang Cc C, Itani SI, et al. Enhanced muscle fat oxidation and glucose transport by ACRP30 globular domain: acetylCoA carboxylase inhibition and AMP-activated protein kinase activation. Proc Natl Acad Sci USA 2002; 99: 16309-13.

20. Wu X, Motoshima H, Mahadev K, Stalker TJ, Scalia R, Goldstein BJ. Involvement of AMP-activated protein kinase in glucose uptake stimulated by the globular domain of adiponectin in primary rat adipocytes. Diabetes 2003; 52: 1355-63.

21. Yamauchi T, Kamon J, Minokoshi Y, Ito Y, Waki H, Uchida S, et al. Adiponectin stimulates glucose utilization and fatty-acid oxidation by activating AMP-activated protein kinase. Nat Med 2002; 8: 1288-95.

22. Combs TP, Wagner JA, Berger J, Doebber T, Wang WJ, Zhang BB, et al. Induction of adipocyte complementrelated protein of 30 kilodaltons by PPAR $\gamma$ agonists: a potential mechanism of insulin sensitization. Endocrinology 2002; 143: 998-1007.

23. Xu A, Wang Y, Keshaw H, Xu LY, Lam KS, Cooper GJ. The fat-derived hormone adiponectin alleviates alcoholic and nonalcoholic fatty liver diseases in mice. J Clin Invest 2003; 112: 91-100.

24. Okamoto Y, Kihara S, Ouchi N, Nishida M, Arita Y, Kumada M, et al. Adiponectin reduces atherosclerosis in apolipoprotein E-deficient mice. Circulation 2002; 106 : 2767-70.

25. Ouchi N, Kihara S, Arita Y, Maeda K, Kuriyama H, Okamoto $\mathrm{Y}$, et al. Novel modulator for endothelial adhesion molecules: adipocyte-derived plasma protein adiponectin. Circulation 1999; 100: 2473-6.

26. Ouchi N, Kihara S, Arita Y, Okamoto Y, Maeda K, Kuriyama H, et al. Adiponectin, an adipocyte-derived plasma protein, inhibits endothelial $\mathrm{NF}-\kappa \mathrm{B}$ signaling through a cAMP-dependent pathway. Circulation 2000; 102: $1296-301$.
27. Cacicedo JM, Yagihashi N, Keaney JF Jr, Ruderman NB, Ido Y. AMPK inhibits fatty acid-induced increases in $N F-\kappa B$ transactivation in cultured human umbilical vein endothelial cells. Biochem Biophys Res Commun 2004; 324: 1204-9.

28. Saha AK, Avilucea PR, Ye JM, Assifi MM, Kraegen EW, Ruderman NB. Pioglitazone treatment activates AMP-activated protein kinase in rat liver and adipose tissue in vivo. Biochem Biophys Res Commun 2004; 314 : $580-5$.

29. Naka T, Nishimoto N, Kishimoto T. The paradigm of IL-6: from basic science to medicine. Arthritis Res 2002; 4(Suppl 3): S233-42.

30. Ruderman NB, Keller C, Richard A, Saha AK, Luo Z, Xiang $\mathrm{X}$, et al. Interleukin-6 regulation of AMPK: potential role in the systemic response to exercise and prevention of the metabolic syndrome. Diabetes 2006; (in press).

31. Park H, Kaushik VK, Constant S, Prentki M, Przybytkowski E, Ruderman NB, et al. Coordinate regulation of malonyl-CoA decarboxylase, sn-glycerol-3-phosphate acyltransferase, and acetyl-CoA carboxylase by AMPactivated protein kinase in rat tissues in response to exercise. J Biol Chem 2002; 277: 32571-7.

32. Ostrowski K, Rohde T, Zacho M, Asp S, Pedersen BK. Evidence that interleukin-6 is produced in human skeletal muscle during prolonged running. J Physiol 1998; 508: 949-53.

33. Ostrowski K, Schjerling P, Pedersen BK. Physical activity and plasma interleukin-6 in humans - effect of intensity of exercise. Eur J Appl Physiol 2000; 83: $512-5$.

34. van Hall G, Steensberg A, Sacchetti M, Fischer C, Keller C, Schjerling P, et al. Interleukin-6 stimulates lipolysis and fat oxidation in humans. J Clin Endocrinol Metab 2003; 88: 3005-10.

35. Pedersen BK, Steensberg A, Schjerling P. Musclederived interleukin-6: possible biological effects. J Physiol 2001; 536: 329-37.

36. Steensberg A, Keller C, Starkie RL, Osada T, Febbraio MA, Pedersen BK. IL-6 and TNF-alpha expression in, and release from, contracting human skeletal muscle. Am J Physiol Endocrinol Metab 2002; 283: E1272-8.

37. $\mathrm{Mu} \mathrm{J}$, Brozinick JT Jr, Valladares O, Bucan M, Birnbaum MJ. A role for AMP-activated protein kinase in contraction- and hypoxia-regulated glucose transport in skeletal muscle. Mol Cell 2001; 7: 1085-94.

\footnotetext{
Eva Tomas

Section of Endocrinology and Diabetes Unit

650 Albany St. X-820

Boston, MA 021 I 8

USA

Tel: + | 6176387191

Fax: + | 6176387094

E-mail: etomas@bu.edu
} 